\title{
Realizing a Progressive Pedagogy: A Comparative Case Study of Two Reggio Emilia Preschools in San Francisco
}

\author{
Marwa Abdelfattah \\ Graduate School of Education, The American University in Cairo, Egypt
}

Copyright (C) 2015 by authors, all rights reserved. Authors agree that this article remains permanently open access under the terms of the Creative Commons Attribution License 4.0 International License

\begin{abstract}
This study aims to uncover how a particular imported philosophy of early childhood education, Reggio Emilia, is implemented in the context of one public and one private preschool in San Francisco. The philosophy of Reggio Emilia is believed to be progressive and to be developmentally appropriate for children in early childhood. The study involved a total of 8 teachers ( 4 in each preschool), 2 program administrators, and 60 children (30 in each preschool and 15 in each observed classroom). Results from the qualitative data analyses reveal that the private preschool maintains a higher degree of fidelity to the Reggio Emilia approach (REA) than does the public preschool. Results also indicate that there are two main factors that contribute to the aforementioned difference in implementation: school resources and teachers instructional choices. This study helps teachers, parents and researchers in the field of ECE better comprehend what contributes to the pedagogical practices at play in different schools depending on their context
\end{abstract}

Keywords Developmentally Appropriate Practice, Reggio Emilia, Teachers' Beliefs, Regulations, Teachers' Instructional Choices, School Resources, Private Preschools, Public Preschools, Qualitative Research

\section{Introduction}

The field of early childhood education (ECE) is contested terrain in which professionals take vastly different stances on proper methods. While there is consensus about the importance of what is commonly referred to in the field as "developmentally appropriate practices" (DAP), the interpretation of this concept is still subject to debate by families, teachers, school administrators, and ECE professionals (New, 1997) [23]. This contestation glosses over the fact that sharp dichotomy between DAP and traditional ECE might not exist in practice as such, with what is labeled as DAP implemented along a continuum from traditional to progressive, depending on school context.
Taking a step back from this debate, this research examines what is really happening inside the public and private classrooms of self-proclaimed developmentally appropriate schools.

In this paper, I examine two preschools in San Francisco, one is private and one is public, that have adopted progressive early childhood methods with a conscious focus on the Reggio Emilia Approach REA- that became trendy in the American ECE as it combines the work of important educational theorists like Lev Vygotsky, Maria Montessori and John Dewey (Wurm, 2014) [30]. I chose these two schools because they are both in the same city and both claim that they implement the same pedagogy despite the fact that one is public and the other is private. This difference is significant in this undertaking as it helps better understand why many preschool teachers in the U.S. think that it is very difficult to be a Reggio-inspired preschool in this country under the presence of many U.S preschool regulations (Wurm, 2014) [30]. In fact, it can be argued that this is one of the reasons why there are very few public Reggio-inspired preschools as public preschools are usually subjected to more regulations. As there is little to no research that compares how a sole imported pedagogy of ECE is adopted in different schools depending on their type, I designed this comparative study of two Reggio preschools guided by the following question: do the two schools' enactments of the REA differ, and how? I argue that school resources and teachers' instructional choices determine the nature of the REA implementation in the classroom. I investigate warrants for this claim by using mixed qualitative methods, which include classroom observation and interviews with teachers and school directors. This study helps teachers, parents and researchers in the field of ECE better comprehend what contributes to the pedagogical practices at play in different schools depending on their context.

\section{Background}

\section{Reggio Emilia}

What is commonly referred to as the REA began after 
World War II in Italy when the Italian government decided to subsidize projects that restore the sense of community in each Italian province. The inhabitants of Villa Cella, an area slightly outside the small village Reggio Emilia, decided to use their government money to build a school: scuola del popolo (school of the people). Guided by this concept school of the people- many schools were created in Reggio Emilia under the supervision of Loris Malaguzzi (1920-1994), a local educator who was the driving force behind the entire movement. Those schools were first brought to international attention in 1991 when the REA was deemed the best in early childhood education according to Newsweek in "The 10 Best Schools" (Wurm, 2014) [30].

\section{Reggio-inspired teaching and developmentally appropriate practice}

According to Wurm (2014), Reggio-inspired teaching is in line with current research about how children learn. The general guidelines of the REA -that revolve around treating children as unique individuals who come to school with knowledge, questions and experience, observing them, collecting and discussing with them their artifacts (what is called in the REA documentation), following their pace and reinforcing their learning through what they are interested inare aligned with the concept of developmentally appropriate practice (DAP). DAP is an important concept that is highly stressed by the National Association for the Education of Young Children (NAEYC)- an oversight body in ECE whose guidelines are used by professionals in the field to assess the quality of different ECE programs. The NAEYC stresses DAP and defines its two dimensions as age appropriateness and individual appropriateness. According to the NAEYC, there are predictable patterns of growth that occur in children during the first 9 years of life. These predictable changes affect each of the domains of development-physical, emotional, social, and cognitive. Knowledge of typical child development provides a framework for an age-appropriate learning environment for teachers (Bredekamp, 1987) [3]. Individual appropriateness, by contrast, acknowledges that each child is unique and therefore that individual growth patterns and timelines will vary. Individual appropriateness also stresses the need to accommodate students' personalities, learning styles, and family backgrounds. According to the NAEYC definition of developmental appropriateness, a quality early childhood education program attends to those individual differences by providing learning opportunities that suit the child's developing abilities, while also challenging the child's interests and understanding (Bredekamp, 1987) [3].

Based on this definition of DAP, the NAEYC recommends that teachers serve primarily as resources for children's self-initiated activity, providing open-ended opportunities for children to explore concrete materials and to interact with one another. The NAEYC discourages teaching basic skills with drills, workbooks, and worksheets; they suggest instead that teachers embed practice with basic skills in everyday, meaningful activities. In the ECE literature, this constellation of practices is referred to as "child-centered" pedagogy (Stipek and Byler, 1997) [28].

The REA is believed to conform to and even to exceed the NAEYC guidelines for DAP (New, 1997) [23]. Those guidelines reflect the professional opinion of most early childhood education experts and are generally supported by research on the effects of instructional approaches on children's learning and level of motivation (Hart, Burts, \& Charlesworth, 1997; Stipek, 1993) [2], [27]. The specific aspects of REA that are echoed by DAP are documentation, advocacy, and participation (New, 1997) [23]. Malaguzzi, the founder of REA, has argued that a proper early education demands professional expertise, strategies of care, and an environment that is appropriate and unique to children's developmental level (Malaguzzi, 1993) [15]. This perspective coincides with traditional interpretations of high-quality early childhood services utilizing well-trained teachers and a self-conscious practice of DAP that involves both age appropriateness and individual appropriateness (Bredekamp, 1987) [3]. Moreover, Malaguzzi argues that the origins of his pedagogy are to be found in teachers' experience with young children on the ground, not in books and articles written by academics working outside of the day-to-day early childhood classroom. REA documentation aims to assist in DAP by requiring teachers of young children to observe and interpret children's development and to document their process and conclusions (New, 1997) [23]. In fact, it has been argued that Reggio Emilia's interpretation of the role of teacher observation and documentation conforms with best practices as articulated by contemporary literature in early childhood education and adheres to even more stringent guidelines than do other DAP practitioners (New, 1997) [23].

\section{Schools context and licensing regulations}

The government intervenes in the preschool market by providing subsidies and imposing regulations on providers. The aim of those regulations is to protect children from potential risks such as harm from injury, disease as well as developmental impairment (Morgan and Azer, 1997) [18]. Regulations specify certain requirements for the education of child care providers, the ratio of children to childcare staff members' and the frequency with which facilities are inspected. Childcare regulations are determined by state governments not by the federal government. Thus, those regulations differ across states. It is also worth noting that childcare regulations impose minimum standards but do not define or attempt to enforce "optimal" standards (Morgan and Azer, 1997) [18]. This explains why it is possible that a given childcare provider complies with all state regulations but still receives a low score on quality rating scales. Furthermore, in some states, state regulations apply for all types of childcare providers except for centers that are affiliated with a church or family day care homes that provide care for only a few children. This means that such centers are not required to obtain licensing in order to operate (Blau and Currie, 2006) [1]. 
In the State of California all sorts of public as well as private preschools are subject to licensing rules. Moreover, there are additional requirements that public and private preschools must meet in order to obtain accreditation from the NAEYC and qualify for funding. An important source of funding in this study is Preschool For All as the public preschool in this research is partner with it. In San Francisco, the First 5 California Children and Families Act established the PFA program so that "every child has equal access to a high-quality preschool program" (PFA, n.d) [9]. PFA offer funding opportunities for families who enroll their children in childcare providers that are partners with it (PFA, n.d). All childcare providers - public or private- must meet the PFA Baseline Criteria 1 and the PFA Provider Assurances ${ }^{2}$ in order to partner with PFA (PFA, n.d).

\section{Critical Literature Review}

\section{Teacher belief systems}

This comparative study necessitates an analysis of the genesis of and continued influences on teacher beliefs about pedagogy. Extant research shows that teacher beliefs affect their classroom practice. Stipek and Byler (1997) [23] found that teachers who express an appreciation of child-centered approaches in ECE tended to particularly value child independence and self-esteem. They have also found that teachers who hold stronger beliefs about basic-skills curricula are less likely to endorse child-centered practices in the classroom. That being said, there are studies that suggest that teacher beliefs about proper pedagogy place more emphasis on developmental appropriateness than do their practices (Charlesworth, Hart, Burts, \& Hernandez, 1990; Charlesworth et al., 1993; McMullen, 1999) [6], [20]. McCarty and colleagues (2001) found that Head Start educators in lower-quality classrooms were more likely to express approval for statements of developmentally inappropriate classroom practices than were teachers in higher-quality classrooms. Another research tested teacher beliefs regarding proper content for preschool reveals that preschool educators from different preschool settings (private, public, family) emphasize the importance of independent child activities, including play and interaction between teacher and child (Lara-Cinisomo, S., Fuligni, A. S., Daugherty, L., Howes, C., \& Karoly, L. 2009) [14]. This study also found great variation in educators' beliefs within center-based programs and across center- and family-based care. It argues that there is no evidence that center-based programs would differ from family-based programs in their approach; it isn't necessarily the case that center-based educators place more importance on a structured, teacher-driven environment while family-based educators

1

http://www.first5sf.org/sites/default/files/page-files/1213 BC_final_0.pdf 2 http://www.first5sf.org/sites/default/files/page-files/12 $\overline{13}$ _PAss_final.pdf depend on unstructured, child-driven practices.

Many of the above studies, however, included only kindergarten teachers. In addition, some of the studies that focus on preschool teachers such as (Stipek and Byler, 1997) [23] ground their argument in interviews with teachers from different programs settings; they do not describe and analyze classroom observations and therefore cannot describe the relationship between teachers' beliefs and their classroom practices. Finally, it is still unclear through the aforementioned studies whether the preschool teachers agreed with the philosophy of the program within which they work or examined what might contribute to an alignment or a mismatch of teacher philosophies and school policies. This study addresses this gap by examining how self-proclaimed Reggio teachers understand the REA and apply it in their classrooms.

\section{Teachers'qualifications}

The literature listed above touches upon the relationship between teachers' beliefs and their practice without considering the origins of the teachers' philosophical orientations. There has been some progress in the latter area; studies identify many factors that influence the beliefs adopted by caregivers and teachers (Buchanan, Burts, Bidner, White, \& Charlesworth, 1998; Hao, 2002; 1999) [4, 13]. Research shows that educational background is an important contributor to teachers' beliefs about early childhood development. Educational background here refers both to the subject's amount of overall education and also to the type of coursework or content of that education. Other studies conclude that overall level of education is the most significant indicator of whether or not teachers adopt a DAP philosophy (Kontos \& Wilcox-Herzog, 2001; Morgan et al., 1994) $[15,22]$. Yet another body of research find that it is not the level but the type of education that matters most in shaping teachers' relationship to DAP (see, e.g., Cassidy, Buell, Pugh-Hoese, \& Russell, 1995) [5-6]; teachers who have taken coursework or engaged in training specific to the acquisition of the knowledge and skills believed to be connected to working effectively with young children have been found to engage in more behaviors associated with DAP (Howes, 1983; Scarr, Eisenberg, \& Deater-Deckard, 1994; Snider \& Fu, 1990) [14, 25, 26].

Another study examines caregivers and teachers of preschoolers, ages 3 to 6 years, in a Midwestern state, and found that an educational background that includes coursework or training specific to working in the field of early childhood education did affect the beliefs held by caregivers and teachers. These beliefs manifested themselves in matters of, for instance, (1) children being allowed to select some of their own activities and the importance of active exploration in children's learning, (2) respect for individual differences in interests and developmental level when planning curricula, and (3) the importance of peer collaboration in play and learning activities and how this collaboration contributes to children's social development (McMullen, M. B., \& Alat, K. 2002) [17]. 
The previous literature is significant in deciphering the origins of teacher beliefs but it does not investigate in depth the relationship between teachers' philosophies and teachers' educational opportunities in the schools in which they teach. This study, by contrast, investigates this aspect to examine how teachers' continuing education can affect their classroom practices.

\section{Comparative Design of Schools}

In this comparative case study I examine two preschools in San Francisco that identify with the REA. San Francisco was the most feasible choice for this study as it is the only nearby site where I was able to find a private and a public preschool that are Reggio-inspired and English immersion. The public school is located in a middle-class neighborhood that is predominantly Latino, and the majority of both the student and teacher body is Latino. The socio-economic status of the public school students varies widely. The private preschool, by contrast, is located in a wealthy neighborhood and serves mostly Caucasian children and a minority of Asian and Hispanic students, and the student body's socioeconomic status is generally high. All of the teachers in the private preschool are native speakers of English from the United States and Australia. See Table 1 for a brief description of each program demographics.

Table 1. Programs Demographics

\begin{tabular}{|c|c|c|c|c|}
\hline $\begin{array}{c}\text { School } \\
\text { type }\end{array}$ & Location & $\begin{array}{l}\text { Student } \\
\text { SES }\end{array}$ & $\begin{array}{c}\text { Teacher } \\
\text { background }\end{array}$ & $\begin{array}{c}\text { Student } \\
\text { background }\end{array}$ \\
\hline Public & $\begin{array}{c}\text { Latino } \\
\text { average SE } \\
\text { neighborhood }\end{array}$ & $\begin{array}{l}20 \% \text { high } \\
20 \% \text { Low } \\
60 \text { average }\end{array}$ & $\begin{array}{c}100 \% \\
\text { Latino- } \\
\text { (immigrants) }\end{array}$ & $\begin{array}{c}20 \% \\
\text { Caucasians } \\
80 \% \text { Latino } \\
\text { (ELL) }\end{array}$ \\
\hline Private & $\begin{array}{c}\text { High SE } \\
\text { neighborhood }\end{array}$ & $100 \%$ high & $\begin{array}{c}90 \% \\
\text { Caucasian } \\
10 \% \text { Asian } \\
\text { (born and } \\
\text { raised in the } \\
\text { US and } \\
\text { Australia) }\end{array}$ & $\begin{array}{c}80 \% \\
\text { Caucasians } \\
20 \% \text { Asians }\end{array}$ \\
\hline
\end{tabular}

\section{Methods}

The methods that I use in this case study are classroom observation and interviews. Observation, according to Geertz [10], enables the researcher to achieve what he calls a "thick description" of her subject. By participating as a "peripheral member" (Rosenbloom, S \& Way, N. 2004) [24] in a progressive classroom, I have the chance to observe how the child-centered pedagogy is practically implemented on a day-to-day basis.

The second method is semi-structured interviews. According to Glesne \& Peshkin [11] one can interview "in search of opinions, perceptions and attitudes," as I do in the case of this study. During interviews, I asked principals and teachers not only about the school's rules and the school's sources of licensing and accreditation but also about how the teachers and administrators perceive those rules and whether they conflict with or conform to REA pedagogy as they understand it. Moreover, Glesne \& Peshkin [11] assert that "interviewing can also put one on the trail of understandings that they may infer from what they observe." I implement this aspect of the method as well; when during observation "I don't see or can no longer see" certain aspects of pedagogy pertinent to my research (Glesne, C.\& Peshkin, A. 1992, P. 64) [11], I inquire about those aspects over the course of additional interviews.

\section{Data}

\section{Collection}

(I agree with you that a section about the limitations should be added. I'm not sure, however, if I should talk much in the limitations section about subjectivity as it might sound as stating the obvious as qualitative research is subjective by default. Please check the Limitations section after the Findings one (p.27) and advice if I should talk further about subjectivity.). The study involved a total of 8 teachers (4 in each preschool), 2 program administrators, and 60 children (30 in each preschool and 15 in each observed classroom). I observed two classrooms, one in each school, over the course of 5 to 7 visits per school. The total hours of observations during each visit are three. The rest of the time spent in the school during each visit was dedicated to interviews with teachers and school administrators. I consulted with the two schools' principals and expressed to them that I wished to observe children from 2.5 to 6 years old. Consequently, each school principal suggested that I observe two of their classrooms: one for children from to 3 to 4 years old and the other for those from 4.5 to 6 years old, which yielded a total of 4 classrooms to observe. Each classroom was run by 2 teachers.

I took field notes regarding behaviors that shed light on the power relations between children and between students and their teachers. One way in which I analyzed power relationships was by observing whether instruction was mandated or mediated and the ways in which teachers responded to the children's needs and decisions. I was able to analyze the student-teacher relationship by considering the dialogue between teachers and children as well as by carefully observing the teachers' body language (including looks, head turns, and touch) in reaction to children's decisions. I observed when children were touched by their teachers in order to see whether they physically interacted with them as a response for their need for affection or as a way to push them to obey instructions. In addition, I looked at how literacy was taught - specifically, whether it was introduced through the children's desire to learn or through an academic session during which the teacher was at the center of the classroom writing on a board. I also observed projects and documentation processes, which are essential to the REA. I looked at how the children's work was documented and built upon. Together, these aspects were 
telling of the interaction between the REA in concept, the teachers' understanding of the REA, and school regulations that ensure schools licensing and accreditation (which revolve around child safety and accountability).

The second method used to collect data was interviews. I interviewed 2 principals and 7 teachers (4 in the private school and 3 in the public school). Each school has more than 3 teachers. However, as the time for observations and interviews was limited to a week for each school, I agreed with the school director to interview only the teachers of the classrooms that I observed. Out of the 6 teachers I observed in the 2 classrooms in the public school, I was able to interview 3 teachers (one lead teacher and 2 co-teachers) ${ }^{3}$. In the private school, I was given the chance to interview the 4 teachers I observed in 2 classrooms (two lead teachers and 2 co-teachers). I inquired about teachers' backgrounds, their perception of the REA, and how they implement it in the school. I was also interested in whether the public regulations to which the schools are subject have any effect on their implementation of REA. My interview protocol for the principals was developed to learn about their backgrounds, how the school came to adopt REA, the general student makeup, the tuition fees, and, most importantly, the rules the school must follow in order to be licensed, accredited, or (in the case of the private school) funded. I explored the extent to which these outside forces influence the implementation of REA. The interview protocol may be found in the appendix.

\section{Analysis}

I conducted several close readings of the interview transcripts, amended field notes, and pertinent documents using methods of grounded theory (Glazer \& Strauss, 1967; Strauss \& Corbin, 1990) [12], an inductive process that uses textual data. In this paper, I code my data using the research questions as guides. Through my first open coding of my field notes and transcribed interviews, I developed a set of initial codes in accordance with the following categories: instruction, child, adult, child-adult interaction, tension, child-centeredness, care, creativity, and imagination. In the second coding pass, I recategorized the descriptive and interpretive codes into multiple inclusive codes depending on their frequency. In order to complete this process, I use the techniques described by Emerson, Fretz, \& Shaw (1995) [8].

\section{Findings}

Results from the study suggest that the implementation of REA in the four private and public classrooms I visited is

3 I interviewed one lead teacher in one classroom and two co-teachers in the other classroom. I had several informal conversations with the lead teacher in the second classroom as well as with the teacher who replaced her when she was on leave. However, because of schedules conflict, I was unable to interview the lead teacher in the second classroom and the teacher who replaced her refused to be interviewed. primarily influenced by three factors, namely: (1) teacher beliefs about REA and the regulations to which each school is subjected; (2) teacher instructional choices; and, (3) the school resources for teachers' continuing education. In the following sections, I lay out each of these factors individually and articulate their subcategories. I do so in two separate sections. In section I, I present the factors that inform the pedagogy's implementation; in section II, I present vignettes from my classroom observations that give a sense of how REA is implemented in the two schools.

\section{Factors that inform the pedagogy's implementation}

\section{Teacher beliefs}

\section{The REA}

In order to understand my participants' beliefs regarding their classroom practice I asked them to describe their ideal pedagogy and the aspects of REA that they most appreciate. All the teachers in the two preschools considered themselves to be REA-inspired teachers who either had previous training with the REA or were introduced to the philosophy when they started working in the schools. Some of the teachers gave responses that demonstrate a coherent understanding of the REA focusing on children-initiated activities, play, research, observation, and documentation and felt this approach intersected with their ideal teaching pedagogy. Other teachers gave very brief general responses around play and children interests.

\section{Public school teachers' responses about the REA}

Teacher Andrew (a pseudonym is used here for confidentiality; see table 2 for the Interview Profile Sample) of the public school clarified why he thinks REA is in line with his ideal pedagogy for young children:

Table 2. Interview sample profile

\begin{tabular}{|c|c|}
\hline Name/Title/ Gender & $\begin{array}{c}\text { Experience in the } \\
\text { two preschools }\end{array}$ \\
\hline $\begin{array}{c}\text { Teacher Andrew/ Lead teacher in the public } \\
\text { preschool/ Male }\end{array}$ & 10 years \\
\hline $\begin{array}{c}\text { Teacher Brenda/ Co-teacher in the public } \\
\text { preschool/ Female }\end{array}$ & 12 years \\
\hline $\begin{array}{c}\text { Teacher Craig/ Co-teacher in the public } \\
\text { preschool/ Male }\end{array}$ & 12 years \\
\hline $\begin{array}{c}\text { Teacher Eve/ Lead teacher in the private } \\
\text { preschool/ Female }\end{array}$ & 2 years \\
\hline $\begin{array}{c}\text { Teacher Dawn/ Co-teacher in the private } \\
\text { preschool/ Female }\end{array}$ & 2 years \\
\hline $\begin{array}{c}\text { Teacher Fran/ Co-teacher in the private } \\
\text { preschool/ Female }\end{array}$ & 1 year \\
\hline $\begin{array}{c}\text { Teacher Holly/ Lead teacher in the private } \\
\text { preschool/ Female }\end{array}$ & 1 year \\
\hline
\end{tabular}

Note. To preserve confidentiality, the names of all the participants were changed.

In my opinion as a teacher, I think the children really need to enjoy what they do, and once they do something that they really enjoy, that they can relate to, they will connect to that. I don't teach them something that is 
abstract to them that is irrelevant to them unless they have an experience with that. I can have the most beautiful presentation, but if the children are not interested in the topic, the kids are not gonna get what I teach. So that's why we observe the children, find out their interest, and we develop what to teach.

Teacher Andrew thus summarizes the REA philosophy as teacher participation, documentation, and observation in service of developing children's skills. His statement indicates that Teacher Andrew has a very clear understanding of the pedagogical philosophy with which his school is affiliated.

Teacher Andrew's colleagues in the public preschool: Teacher Craig and Teacher Brenda gave responses that reduced the underpinning principle of the REA to "following children interests" without really explaining how this idea can be put into action. Both teachers also revealed that Reggio Emilia is a pedagogy that does not conflict with the district, licensing and Preschool for All requirements.

\section{Private school teachers' responses about the REA}

Teacher Eve from the private school said the following about her ideal teaching pedagogy and how it intersects with REA:

It's very open-ended, kind of leaves it open to the interpretation and the documentation observation of teachers. I mean really getting to know your kids on a deeper level, you know all this documentation that you do. So I think that, and I say it of every teacher, it kind of keeps you on your toes and it challenges you as an educator to kinda keep bettering yourself as a teacher.

Teacher Dawn in the private school was the only teacher who admitted to a disconnect between what she believes is right for children and the principle of documentation in Reggio. She argues,

In terms of preschool for me it's all about having fun and making sure that their day at school is enjoyable and they love learning and that they're passionate about learning, curious and all that sort of stuff. And to me it's not necessarily about writing every single word that they say down just to capture every single thing that they say... that part of it is secondary to my actual teaching and my being involved with the kids.

Through this quote we can see that Teacher Dawn demonstrates a clear understanding of the REA and is able to verbalize her critique of it.

Teacher Holly of the private school also gave a response that shows her degree of familiarity with the REA. She points out that there are different approaches to "doing Reggio." For instance, she explains that before arriving at her present school she worked in another Reggio preschool that was more "research-based," which meant "doing a lot of questioning" to reflect on the children's work.
All of the teachers interviewed in both schools consider themselves to be Reggio teachers. As shown above, there is evidence that all of the private school teachers are aware of the REA general guidelines. In the public school, however, Teacher Andrew was the only teacher who demonstrated an understanding of the REA that goes beyond appreciating children-initiated activities. It is also important to note that all the private school teachers focused on the importance of projects in the REA while none of the public school teachers mentioned them in the interviews. This aspect is an important first step in understanding variations in implementation of REA.

\section{The regulations}

The two schools in this research do not have to abide by the same state regulations. Both schools should follow the state of California Licensing rules. The public school, however, is subjected also to the district requirements and the San Francisco Preschool for All initiative expectations. Therefore, the public preschool is subject to more assessment and evaluations that insure the school is meeting the district and funders expectations. Thus, those regulations are a part of the everyday life in the public school but are not the case for the private one.

My data, however, shows that we cannot look solely at preschool regulations in studying the implementation of REA in the classroom. In fact, my data shows that it is not school regulations per se but rather the teachers' perception of them that informs their practices in the classroom. That being said, this analysis only applies to the public school, which is subject to regulation by the state of California, the district, and the San Francisco Preschool for All. The public school children also undergo several tests whose results determine the amount of state funding the schools receive. Teacher Andrew commented on the rules to which his public preschool is subjected:

The district wants the kids to learn all 26 letters upper and lower cases by the time they enter kindergarten, they want the children to write their first name, they want the children to learn all the colors they need, they want the children to recognize the numbers 1 to 20 and to write at least 1 to $10 \ldots$ that's where there was a conflict with Reggio because in Reggio we teach as we go but if it is almost the end of the year and the kids they are not really into letters...some children are not interested in any thing...in Reggio...it is not that they don't teach letters....they teach it with more passion...more slow pace I guess, we have to provide activities in order to provide that.

While Teacher Andrew admires REA, he believes that it is an inappropriate tool for the fulfillment of district requirements. This ambivalence is also manifested in his comment about his perception of the district rules:

To be honest with you, I think that has really helped the kids, I'm not saying that the district goals are bad, I'm 
just saying that we just need the time for us to plan and organize ourselves better. If we had more time, I think we will be able to work with Reggio and at the same time with the school district goals but I think that the district rules it is not just the district, it's California, it's the US, they want our kids to learn...it just that we need to have more time and have better salaries.

As much as he admires Reggio, Teacher Andrew recognizes that there is merit in the district requirements; it aims to ensure children's basic education. He then refers to "time" and "organization" as two resources that might help him to achieve state requirements using the Reggio method. In short, Teacher Andrew argues that the problem lies neither with the district requirements nor with REA - it lies with the teachers' access to resources.

On the other hand, Teacher Craig and teacher Brenda from the public preschool offered a simpler analysis. Both of them stated that the district rules do not conflict with the REA. When I asked Teacher Craig how he perceived public preschool regulations, he said simply, "We need regulations in order to function; other than that it is chaos." When I asked Teacher Craig and Teacher Brenda whether the district expectations conflict or not with the REA, both teachers unlike Teacher Andrew, said that in this particular school teachers have the freedom to adopt the REA without any constraints. Thus, teacher Dimitri, like Teacher Brenda, did not recognize the tension between REA and public regulations that Teacher Andrew articulated. It can even be argued that their responses are compatible with their reported general understanding of the REA.The public school administrator had a more straightforward response regarding the intersection of the REA with the regulations the school should abide by. In an attempt to flesh out this dimension she said:

The requirements of the district: we must be preparing our children for kindergarten readiness. Kindergarten readiness includes, in the estimation of our school district, it includes particularly phonological awareness and socio-emotional skills. But all the academic skills that maybe you and I might not look at as early childhood, maybe we might look at things that maybe might happen at kindergarten, they expect them to be done now. We also have funders from Preschool for All from the site of California, San Francisco rather, which is universal preschool and they measure quality by assessing our teachers' education, by coming into classrooms, outside observers, assessing, counting, how long children wait, what they are learning, what materials we have, what training we provide, how we interface with children. And then there is also the CLASS -an observational skill that they use a lot in Headstarts... it emphasizes the positive and negative climate, the organization of the classroom, when we're talking about the organization we're talking about the scheduled day and the balance of direct and indirect teaching. So that's difficult with Reggio. For example, according to our educational director, children must sign in their names every day, that's not a typical Reggio setting.

The public school administrator response shows that there is a difficulty to abide by the district requirements using the REA. Her response also shows that the tension relies mostly in the tools of assessment rather than the regulations per se. In other words, the administrator's reflection asserts that meeting the assessors' expectations creates a certain setting that makes the implementation of the REA impossible.

My interviews with the private preschool teachers about the same topic yielded very different results. When I directed questions about regulations to the private school teachers, they did not understand what I was talking about. When I specified that I was talking about licensing rules, Teacher Dawn and Teacher Eve asked me to refer my questions to the director; they believed that those rules are irrelevant to their classroom practices. The private school teachers explained that they develop their own curriculum at the beginning of the year and decide with their co-teacher about how to proceed. I then interviewed the private preschool administrator and owner about how regulations shape the school's policies. She said,

We only have to follow the licensing rules... I mean those are all the state rules ... but other than that... like I know public schools have to do more of that kind of stuff but we don't have to do that... our main body is licensing. Child services are who we go by.

The responses of the private school teachers and administrator demonstrate that the private school is not subject to the same constraints as is the public preschool to a point that the teachers in the private schools did not understand clearly my question about regulations. The private school teachers' responses also showed that they are very much in control in terms of planning and organization which makes them- according to their responses- appreciate working in this school.

\section{Teacher backgrounds and continuing educational opportunities}

In addition to teachers' pedagogical commitments, both teachers' educational backgrounds and also the amount and kind of professional development they are offered inform their implementation of the REA. My interviews with the public school teachers revealed that none has an undergraduate or graduate degree in early childhood education. However, they all had previous experience with youth or children before coming to the school and they are all Latinos for whom Spanish is their first language. They were all hired over 10 years ago by the erstwhile school director, who was responsible for introducing the REA to the school and who trained the incoming teachers according to its tenets. When I asked what teachers would change if they had the 
power to enhance the school's professional development program, Teacher Andrew said the following:

Teachers need time... I think I'd give more time for teachers to meet as a team because a lot of the times we need to talk about the children, what is Raoul trying to say? What is Angie trying to say? If we don't have that time, that are a lot of pieces of projects that we don't develop or elaborate anymore because you don't have the time to talk....So if there is one thing I would change, I would give teachers the time to meet maybe once a week for 2 hours...We used to have that like 5 years ago but they cut the fund for those meetings and now we meet every other week for 1 hour and usually we meet just to talk about other issues not the kids.

This statement touches upon the public school teachers' need for reflective group meetings as a resource that can contribute to their professional growth. The opportunity for teachers' continuing learning is heavily stressed by DAPS and the REA; both of which emphasize the need for teachers to observe, document, and discuss pedagogical strategies with one another. As Teacher Andrew's above statement shows, the public school teachers are not offered the opportunity to hold weekly meetings at which to discuss students' progress and strategies for professional improvement. This situation, combined with the fact that none of the teachers in the public preschool has a degree in ECE, distances the schools' practices from REA and from DAP writ large.

Unlike the public school teachers, all the teachers in the private school have Bachelor's or Master's degrees in early childhood education. Also, some of them are fresh graduates- a factor that the private school administrator sees as an advantage. In this regard, she said: "I like hiring fresh graduates; they come with fresh ideas and they contribute a lot of the program."

In addition, according to the teachers' testimonies and my observations in the teachers' meeting room, they complete various readings on children pedagogy, discuss them, and together decide what aspects of the research are appropriate to apply in their classrooms. Furthermore, they have and are responsible for implementing the practices outlined by a workshop handbook entitled "Responsive Language and Teaching." All the private school teachers indicated that they complete classroom observations every now and then and take notes so that they can continue to develop professionally. As Teacher Holly said: "I do a lot of observations and I take a lot of notes and this helps me with my own research. I'm not just teaching, I'm also doing research." For a brief description of all the factors affecting the implementation of the REA, see Table 3. Each factor in the table is given a score from 1 to 4 depending on its strength or weakness in affecting positively the teachers' adherence to the REA.
Table 3. Strength of factors affecting the implementation of the REA in the public and the private preschools

\begin{tabular}{|c|c|c|}
\hline $\begin{array}{c}\text { Factors affecting the } \\
\text { implementation of the REA }\end{array}$ & Private school & Public school \\
\hline Teacher beliefs (DAP and REA) & 4 & 2 \\
Teacher educational background \\
$\begin{array}{c}\text { Teacher educational opportunities } \\
\text { in schools }\end{array}$ & 4 & 1 \\
$\begin{array}{c}\text { Teacher instructional choices } \\
\text { Fidelity to the REA }\end{array}$ & 3 & 1 \\
\hline
\end{tabular}

Note. $0=$ Lowest score, $4=$ Highest score

I argue that all of the aforementioned conditions result in a remarkable difference between the private and public teachers' attitudes toward REA. The teachers' beliefs do not evolve independent of other factors; the teachers' educational backgrounds, the fact that one school is subject to more regulations than is the other, and the presence or absence of school resources to train teachers and encourage their professional development all shape teachers' beliefs. In the following section, I explore the relationship between those beliefs and REA implementation in the two schools.

\section{II- Implementation}

The classroom observations reveal a close relationship between the private school teachers' perception of the REA and their classroom practice. The case of the public school teachers, by contrast, shows that there is a distinct mismatch between their understanding of the REA and their implementation of it in the classroom. The educational backgrounds of the teachers together with the nature of their training are distinctly reflected in their classroom comportment. In order to illustrate the findings, in this section I present vignettes from my observations that focus on evidence of responsive teaching and language techniques (or on the absence of this evidence) in the classroom. I centered my observation on those techniques because they are useful tools in understanding the role and position of the teacher in the classroom and her/his perception of children and how they learn which can help understand how the REA principles are taken into consideration in the two schools.

After spending 15 hours in each school-around 7 hours in 2 classrooms in each school-I was able to observe how both schools' teachers spoke to children, and found marked differences between the two schools. In the private school, I noticed a clear similarity in the language used by the 4 teachers I observed. Discursive regulation is not apparent among the public school teachers; only one of them used any semblance of responsive language, and I did not find evidence that the other 3 teachers were self-aware about their language in relation to responsive language guidelines.

\section{Public school}

The following vignette from my observations illustrates the public school teachers' disregard for REA-oriented 
language. A student in the public school asked the teacher for an orange, saying, "I want an orange;" then the teacher corrected him by saying, "Say, may I have an orange, please?" This constitutes a straightforward form of instruction; it immediately corrects the child language. This straightforward regulative discourse is also apparent when Teacher Andrew manages conflicts between children. In these situations, he is the focal point of the classroom. One day, children in Teacher Andrew's group were complaining about a child who doesn't want to play with his friend. Teacher Andrew arranged the children in a circle and addressed the child in question, who was among them. Teacher Andrew stood in the middle of the circle, his two hands behind his back; he inclined his head towards the child in question and told him the following:

Your friend is basically begging you to play with him and you say no. You know that this is mean? You guys know what is being mean? Ok let's have an agreement: the more you play with him, the more I will play with you.

Here we see that Teacher Andrew is not assuming the role of mediator but rather that of lecturer. Despite his good intentions, he aggravated the situation; afterwards the child in question went back to the other child that complained about him and told him plainly, "I don't like you." This anecdote also shows that Teacher Andrew is trying to mediate the virtues of friendship and kindness through creating incentives for the children. In this situation, we see that he constitutes in himself the incentive; if the boy plays with his friend, Teacher Andrew is going to play with him and if he doesn't he is going to be deprived from this privilege.

The idea of "following children's interests" that the public school teachers talked about in the interviews was also not apparent in their classroom practices. In fact, I found evidence that contradict this claim:

I want to draw those vases. said a child to one of the teachers.

Well this depends on the table you are going to be in. ${ }^{4}$. Answered the teacher.

The example above shows us that there was a possibility for a child-initiated activity to occur but the teacher interrupted it, as she was keen to get the children to follow her structure of the class activity. The eagerness to drive children to follow teacher-led activities is also apparent in play activities:

Teacher Teresa arranged children in a line and asks them not to touch each other's hands. "You move in this direction...you are not following the directions, you need to listen! Now you face the circle, now you put your hands on your waste, now you shake it, you shake it like a milk shake."

4 Because each table has two different vases and children will have to sit on the tables according to the their name tags on them.
Teachers' persistence to make children follow the classroom rules were also apparent in the way they interacted physically with children. Teacher Teresa asks a girl who was about to wash her hands: "Are you in line Ashley? No, no you need to get in line" then she reaches out to Ashley's arm to move her body to the end of the line.

\section{Private school}

I did find evidence, however, that the way teachers in the private school respond to children's conflicts is consistent with responsive teaching. The following anecdote illustrates this adherence to responsive teaching. Lara decided to help Beth with her drawing, which was intended to be a letter to her parents. She added something in the letter that Beth didn't like; Beth thought Lara had ruined the whole letter. Beth then started crying and insisted to Lara, "You messed up the heart." Lara responded "No I didn't" and started crying as well. Teacher Fran was silent, crossing her arms. She asked them, "Do you guys need a hug? Would that make you feel better?" Beth and Lara then started talking about what went wrong. Teacher Fran then told them, "Am happy you guys are talking about it." Beth and Lara finally decided to make a new drawing together. Teacher Fran responded: "I'm really proud of you guys, you worked it out!"

In terms of children-initiated activities, teachers in the private school were keen to finish projects that the children started at the beginning of the year, which sometimes interrupted children's eagerness to have more time in completing an activity they were working on. The transition from an activity to the other (especially to work on projects) throughout the day sometimes frustrated the children. However, given the fact that the school is rich with material, children were given the chance to make a lot of choices within the timespan of each activity. The following anecdote clarifies this point. Teacher Dawn was working with a girl on drawing a letterbox for the fairies and they were trying to draw a matching handle. Teacher Dawn said: "Come with me Lily, am gonna show you some material that you can maybe use to make your handle." After arriving to the art room, Teacher Dawn adds: "Have a look Lily and choose what you think can work." Lily takes about three minutes staring at the material in the art room. She then takes a button-sized piece of wood and hand it to the teacher. Teacher Dawn makes the shape of a box on her leg and asks Lily to put the handle on it to see if it fits. "This is a great choice Lily, let's go back to the classroom, take the handle with us and try to draw it" concludes Teacher Dawn.

The difference in tone and approach between the two schools' teachers was consistent throughout the day, and it was reflected in many aspects of the childcare the two systems offered. For example, the difference in methodology was apparent when solving children's internal conflicts (children in the private school were more encouraged to figure things out on their own), when ensuring safety (children in the private school where allowed to take more 
risks during fieldtrips ${ }^{5}$ ), during play (children in the private school were given more chances to structure play), during snack time (children in the private school were given more chances to talk with each other), and during circle time (children in the private school were given more space to express their views and were less excluded from the circle- a situation that happened repeatedly in the public school). The use of language is also related to the status and tangible presence of the teacher in the classroom. Because most of the teachers' discourse in the public preschool consists of direct instruction, their voices are most audible; and when children speak, their speech is directed to their teachers and rarely to their peers. On the other hand, in the private school, the children's voices are most audible; they are louder and clearer than those of the students in the public school ${ }^{6}$. I noticed that the private school teachers are self-conscious about their roles as facilitators, and their use of language conforms to the guidelines offered in the document concerning responsive language during the teaching workshop provided by the school.

\section{Limitations}

There are two major limitations in the study. The first is the subjective character of this undertaking that is traditionally rooted in qualitative investigations. The second limitation is related to the first one. Due to the length requirement of this paper, the researcher had to make a subjective selection of the data which resulted in focusing on certain guidelines of the REA while eliminating other distinctive features of it such as the Project Approach. Although data regarding this aspect was collected by the researcher and touched upon slightly in this paper by tackling the importance of child-initiated activities (which is a primordial factor in the Project Approach), the focus had to be limited to teacher instructional choices and the factors that influence them. In addition, the fact that this comparative study placed a lot of emphasis on school regulations and the public and private schools dichotomy, left little space to tackle more aspects of the REA guidelines. Thus, to respect the required paper length and to avoid incoherence, the researcher had to dedicate more attention to certain guidelines of the REA more than others.

\section{Discussion}

The findings section shows that multiple factors influence how the REA is implemented in the public and private preschools. Both schools under scrutiny claim that they are

5 Taking risks here mean being allowed to run more freely, climb trees and carry small rocks without a lot of intervention from teachers. They were, however, watching the children closely and intervened whenever needed.

6 This is also because most of the children in the public school are English Language Learners while all the children in the private school are English native speakers.
Reggio-inspired, but they exhibit different levels of fidelity to the Reggio philosophy. The origins of this difference can be summed up under two umbrella categories: resources and teachers' instructional choices.

\section{Resources}

The subcategory of "resources" includes teachers' beliefs, educational backgrounds, and continuing educational opportunities. I developed this category because the findings showed that the teachers' philosophical orientation regarding pedagogy is significantly shaped by their education. Moreover, their practice is affected by the educational opportunities offered in their current job such as having the space and time to observe children and organize reflective sessions with one another to discuss about pedagogy and strategies of care. In the following pages, I explain how the educational background of the teachers relates to school resources. Then I move on to discuss how schools could offer educational opportunities for teachers that contribute to their professional growth and probably compensate for their lack of advanced degrees in early childhood education.

In the private school, all the teachers had graduate or undergraduate 4-year- degrees in ECE. In addition, most of them were newly hired (none of them had spent more than 2 years in the school), while the teachers in the public school who were included in this study spent between 10 to 20 years at the school. It can be argued that the teachers with recent advanced degrees in ECE are attracted to private schools because they offer higher salaries than do many public schools. Indeed, teachers at the public preschool in this study expressed their frustration with their salaries, especially with the lack of financial reward for seniority. This hypothesis about the cause of the disparity of teacher education between the two schools is supported by the work of Vandell and Wolfe (2000) [29], who found that typical childcare salaries are probably not sufficient to attract and retain staff members who have the training and education required to structure emotionally supportive and cognitively stimulating learning environments.

Alternatively, it may be the case that the private preschool attracts younger, more educated teachers because the stronger candidates were attracted to the program's philosophy and the school culture. All the private school teachers revealed that they choose to work in this school because its philosophy matches their ideal teaching pedagogy and because they felt that they had agency in terms of putting into action what they have learned in graduate and undergraduate schools and believed to be appropriate for children. This point is important to take into consideration because it appears that the younger teachers tend to have a more sophisticated and current understanding of the REA and DAP. Fuligni, Howes, Lara-Cinisomo \& Karoly (2009) [17], however, show that public school teachers are more qualified than private and family childcare providers. Therefore, I suggest that more research is needed to understand the difference in terms of qualification and competence between public and private preschool teachers 
(especially preschools that work with imported relatively new pedagogies).

Additionally, my research puts forward a third hypothesis: it may be that teachers' deficiency in pedagogical education can be compensated for by educational opportunities available to them in their workplace. My findings show, for instance, that two of the private preschool teachers were only introduced to the REA when they arrived at the school. Both these teachers and their administrator stated in the interviews that the incoming teachers have received a great deal of training inside the school and are resultantly up-to-date with ECE literature. Teachers in the private preschool, as previously stated, also have the chance to research while working at the school. This means that they use the school resources to produce research-a privilege that the public school teachers lack. In fact, the public preschool teachers stated that they do not have enough time to meet once a week to discuss the children's development. As shown in the findings, one interviewee stated that the public school teachers used to regularly meet, but that the funding for those meetings was cut. What's more, the private school teachers seem to be significantly influenced by the school's workshops. The document that outlines responsive teaching and language guidelines makes this clear. This document summarizes DAP principles and gives the teachers examples of how to respond to certain situations using appropriate language and teaching strategies. I observed that the teachers in the private school largely follow the manual's recommendations for how to speak with, listen to, and resolve the conflicts of their students. Even the way the teachers touch the children in their class appears to be influenced by the guidelines offered during the school workshop.

This finding is supported by previous research that shows that training specific to working in the field of early childhood education affects caregivers' beliefs. Studies show that education can change professionals' opinion about, for example, (1) children being allowed to select some of their own activities and the importance of active exploration in children's learning, (2) respect for individual differences in interests and attention to developmental level when planning curricula, and (3) the importance of peer collaboration in play and learning activities and how this collaboration contributes to children's social development (McMullen, M. B., \& Alat, K. 2002). McMullen and Alat (2002), however, show that there is no evidence that special training of teachers affects Teacher-Directed/Teacher-Control and Child-Centered Literacy Activities.

The last suggestion that the findings put forward in terms of school resources is material. The private school is certainly more equipped in terms of provocative material for children than the public school. It was clear that this material participated in triggering child-initiated activities and helped the teachers to a great extent in building up on children's imagination. If the public school succeeds in providing more material, the public school teachers concern about the "children who are not interested in anything" 7 can be remedied. Provocative material can help both the teachers and the children to create together a richer learning experience.

\section{Teachers'instructional choices}

As shown in the findings section, teachers' choice is integrally related to the regulations to which they are subject. In the case of the public preschool, both the program administrator and one of the teachers betrayed anxiety during their interviews about the district requirements surrounding literacy and safety. While most of the teachers in the public preschool seemed to appreciate the district rules, some of them felt constrained by the regulations and felt it impeded the proper practice of the REA. The public preschool administrator went so far as to report to me that it is "impossible to be Reggio" in the school setting, since the district educational requirements must be achieved and children's learning must be organized around deadlines. The public school administrator also shared an insight about the metrics that the district uses to evaluate the program. She said that the assessors "take snapshots" of what is happening in the classroom instead of initiating a sustained evaluation, which influences classroom practices.

The private school teachers, on the other hand, are not anxious about rules imposed by external bodies. They have the freedom to organize activities and set expectations with their co-teachers. Most of the concerns that the teachers expressed were about teachers' research and some aspects of the REA that they do not personally support. No external assessors visit their classrooms or test their children; they are not under the same pressures as is the public preschool. That being said, the study shows that one cannot claim that there is a direct causal relationship between the public rules (whether the school is subjected to them or not) and the faithful implementation of REA. Would it be better here if I said: "That being said, based on the results of the study, it is unclear whether we can draw a conclusion that there is a definite causal relationship between the public rules and teachers' instructional choices (being more faithful to the REA guidelines) as there are other factors that come into play such as teachers' belief, educational background and continuing education opportunities."?

Wurm [30] stresses on this point by arguing that "licensing is not an excuse" to be inspired by the environment and the practices of Reggio. She argues that teachers' complaints about the impossibility of adopting the REA because of the licensing guidelines in the U.S. are very common. In this context, Wurm [30] reminds her readerspreschool teachers-that while it is true that schools in Reggio Emilia, the city in Italy, are not restricted by numerous licensing rules, Reggio programs did not begin where they are today; they had to face and overcome

7 Like shown in Teacher Andrew's response in the interview. 
challenges in their history as well. Wurm [30] then suggests that instead of dismissing the possibility of implementing the REA because of regulations, teachers can ask themselves what they really want their students to have and then "go to battle for it" by opening dialogue with the licensing agency and conduct research to support their decisions about the experiences they want their students to have.

\section{Conclusions}

To conclude, neither of the two preschools fully conforms to the REA guidelines. However, resources and teachers instructional choices are the two major factors that allow the private school to be more loyal to the philosophy than is the public one, where the practice of the REA seems to be reduced to play, which the teachers structure. This study shows that the name, kind, and reputation of a school's putative philosophy are not what ensure its proper implementation. Resources and teachers instructional choices are the two main components that could lead to the successful realization of schools' pedagogical visions. My study also suggests that most of the obstacles faced by the public preschool can be remedied with a moderate reorientation of resources and a change of perspective. Teachers in the public preschool need time as a resource to organize reflective group meetings where they discuss what they see in the classroom as well as updated literature in the field. Teachers in the public preschool also need to be given incentives for such an initiative that implies extra work. In addition, providing their classes with more provocative material could really enrich their instructional choices and make it more developmentally appropriate. Furthermore, as suggested in the discussion section, teachers need to determine what experience they desire their students to have in the classroom and stand up for their visions even if this means renegotiating the rules.

Finally, I suggest that there is a need for more practical research in this field. Such research would not attempt to assess philosophies of ECE based on whether they identify as "basic-skills" or "child-centered"- two buzzwords in the contemporary field of ECE - but rather would examine how these philosophies are implemented and what might lead to their success or failure in particular contexts.

\section{Appendix}

\section{Interview protocol for principals}

1) How did the idea of adopting Reggio Emilia come about in your school?

2) How is the pedagogy implemented in your school? Could you walk me through a typical school day in your preschool?

3) What are the different bodies (private funder, legal organizations, public officials) that you communicate with that have an impact on the implementation/philosophy of your program?

Follow-up questions: Can you tell me a little bit about these communications and how you experience them? What are the most challenging or positive aspects in those communications? Can you give me examples?

1) What are the rules that you need to follow to receive accreditation/licensing?

2) What would you wish to change in the regulations that your school is subject to?

\section{Interview protocol for teachers}

1) How did you come to teach in this school?

2) Could you walk me through a typical school day in your preschool?

3) What is the ideal teaching pedagogy for children in your opinion?

4) How did you learn about the Reggio Emilia pedagogy?

5) As a teacher, what rules do you need to follow to be held accountable?

6) Do these rules/standards conflict with or reinforce your teaching philosophy?

7) If there is anything that you wish to change about those standards, what would they be?

\section{REFERENCES}

[1] Blau, D., \& Currie, J. (2006). Pre-school, day care, and after-school care: Who's minding the kids?. Handbook of the Economics of Education, 2, 1163-1278.

[2] Hart, C. H., Burts, D. C., \& Charlesworth, R. (Eds.). (1997). Integrated curriculum and developmentally appropriate practice: Birth to age eight. Suny Press.

[3] Bredekamp, S., \& Copple, C. (Eds.). (1997). Developmentally appropriate practice in early childhood programs serving children from birth through age 8 (Rev. ed.). Washington, DC: National Association for the Education of Young Children.

[4] Buchanan, T.; Burts, Diane C.; Bidner, J.; White, V. F.; \& Charlesworth, R. (1998). Predictors of the developmental appropriateness of the beliefs and practices of first, second, and third grade teachers. Early Childhood Research Quarterly, 13(3), 459-483.

[5] Cassidy, D. J.; Buell, M. J.; Pugh-Hoese, S.; \& Russell, S. (1995). The effect of education on child care teachers' beliefs and classroom quality: Year one evaluation of the TEACH Early Childhood Associate Degree Scholarship Program. Early Childhood Research Quarterly, 10(2), 171-183. EJ 508 860.

[6] Charlesworth, R.; Hart, Craig H.; B., Diane C.; \& Hernandez, S. (1990, April). Kindergarten teachers' beliefs and practices. Paper presented at the annual meeting of the American Educational Research Association, Boston.

[7] Charlesworth, R.; Hart, Craig H.; B., Diane C.; T., Renee H.; Mosley, J.; \& Fleege, P. O. (1993). Measuring the developmental appropriateness of kindergarten teachers' 
beliefs and practices. Early Childhood Research Quarterly, $8(3), 255-276$.

[8] Emerson, R. M., Fretz, R. I., \& Shaw, L. L. (2001). Participant observation and fieldnotes. Handbook of ethnography, 352-368.

[9] First Five San Francisco Children and Families Commission. (n.d). Preschool For All. Retrieved from: http://www.first5sf.org/programs/preschool-all

[10] Geertz, C. (1977). The interpretation of cultures. New York. Basic Books.

[11] Glesne, C., \& Peshkin, A. (1992). Becoming qualitative researchers: An introduction. White Plains, NY: Longman.

[12] Glazer, B. G., \& Strauss, A. L. (1967). The discovery of grounded theory: Strategies for qualitative research. New York: Aldine de Gruyter.

[13] Hao Clarke-Stewart, K. A.; Vandell, D. L.; Burchinal, M.; O'Brien, M.; \& McCartney, K. (2002). Do regulable features of child-care homes affect children's development? Early Childhood Research Quarterly, 17(1), 52-86.

[14] Howes, C. (1983). Caregiver behavior in center and family care. Journal of Applied Developmental Psychology, 4(1), 99-107.

[15] Kontos, S., \& Wilcox-Herzog, A. (2001). How do education and experience affect teachers of young children? Young Children, 56(4), 85-91. EJ 635792.

[16] Lara-Cinisomo, S., Fuligni, A. S., Daugherty, L., Howes, C., \& Karoly, L. (2009). A qualitative study of early childhood educators' beliefs about key preschool classroom experiences. Early Childhood Research \& Practice, 11(1), 1-8.

[17] Malaguzzi, L. (1993). For an education based on relationships. Young Children, 49(1), 9-12.

[18] McCarty Charlesworth, R.; Hart, C. H.; Burts, D. C.; Thomasson, R. H.; Mosley, J.; \& Fleege, P. O. (1993). Measuring the developmental appropriateness of kindergarten teachers' beliefs and practices. Early Childhood Research Quarterly, 8(3), 255-276.

[19] McCarty, F., Abbott-Shim, M., \& Lambert, R. (2001). The relationship between teacher beliefs and practices, and Head Start classroom quality. Early Education and Development, 12(2), 225-238.

[20] McMullen, M. B. (1999). Characteristics of teachers who talk the DAP talk and walk the DAP walk. Journal of Research in childhood Education, 13(2), 216-230.

[21] McMullen, M. B., \& Alat, K. (2002). Education matters in the nurturing of the beliefs of preschool caregivers and teachers. Early Childhood Research \& Practice, 4(2), 1-8.

[22] Morgan, G., \& Azer, S. (1997). A primer of child care licensing 1997: Its role in public policy. Institute for Leadership and Career Initiatives, Wheelock College.

[23] New, R. S. (1997). Reggio Emilia's Commitment to Children and Community: A Reconceptualization of Quality and DAP. Canadian Children, 22(1), 7-12.

[24] Rosenbloom, S. R., \& Way, N. (2004). Experiences of discrimination among African American, Asian American, and Latino adolescents in an urban high school. Youth \& Society, 35(4), 420-451.

[25] Scarr, S.; Eisenberg, M.; \& Deater-Deckard, K. (1994). Measurement of quality in child care centers. Early Childhood Research Quarterly, 9(2), 131-152.

[26] Snider, M. H., \& Fu, V. R. (1990). The effects of specialized education and job experience on early childhood teachers' knowledge of developmentally appropriate practice. Early Childhood Research Quarterly, 5(1), 69-78.

[27] Stipek, D. J. (1993). Motivation to learn: From theory to practice.

[28] Stipek, D. J., \& Byler, P. (1997). Early childhood education teachers: Do they practice what they preach? Early Childhood Research Quarterly, 12(3), 305-325.

[29] Vandell, D., \& Wolfe, B. (2000). Child care quality: Does it matter and does it need to be improved? (Vol. 78). University of Wisconsin-Madison, WI: Institute for Research on Poverty.

[30] Wurm, J. (2014). More working in the Reggio way. St. Paul, MN: Redleaf Press. 